Table 1. Comorbidities. Comparison between axial-PsA and AS. OR: odds ratio, MACE: Major cardiovascular events. * adjustments are reported in the text

\begin{tabular}{|c|c|c|c|c|c|}
\hline Comorbidities & $\begin{array}{l}\text { axial-PsA } \\
(n=79)\end{array}$ & $\begin{array}{l}\text { AS } \\
(n=129)\end{array}$ & $\begin{array}{l}\text { Crude OR } \\
(95 \% \mathrm{Cl})\end{array}$ & $\begin{array}{l}\text { Adjusted OR } \\
(95 \% \mathrm{Cl})\end{array}$ & alue \\
\hline $\mathrm{MACE}^{\star} \mathrm{n}(\%)$ & $4(5.1)$ & $6(4.6)$ & $0.91(0.25-3.34)$ & $1.73(0.32-9.34)$ & 0.526 \\
\hline Dyslipidemia n (\%) & $37(46.8)$ & $45(34.9)$ & $0.61(0.34-1.07)$ & NA & 0.108 \\
\hline Hypertension* n (\%) & 27 (34.2) & 24 (18.6) & $0.44(0.23-0.83)$ & $1.11(0.38-3.21)$ & 0.843 \\
\hline $\begin{array}{l}\text { Diabetes mellitus* } \\
\mathrm{n}(\%)\end{array}$ & $12(15.2)$ & $10(7.7)$ & $0.47(0.19-1.14)$ & $1.65(0.43-6.29)$ & 0.463 \\
\hline Depression* n (\%) & $19(24.1)$ & $16(12.4)$ & $0.44(0.21-0.93)$ & $0.48(0.22-1.07)$ & 0.07 \\
\hline Osteoporosis* n (\%) & $3(3.8)$ & $10(7.7)$ & $2.13(0.57-7.98)$ & $2.40(0.56-10.18)$ & 0.235 \\
\hline Malignancies* $\mathrm{n}(\%)$ & $3(3.8)$ & $3(2.3)$ & $0.60(0.12-3.06)$ & $0.87(0.16-4.70)$ & 0.870 \\
\hline
\end{tabular}

Conclusion: AS and axial-PSA have certain clinical and radiologic differences. Comorbidities were comparable, while depression was more common in axial-PsA. Disclosure of Interests: George E. Fragoulis: None declared, Maria Pappa: None declared, Gerasimos Evangelatos: None declared, Alexios Iliopoulos: None declared, Petros Sfikakis Grant/research support from: AbbVie, Pfizer, MSD, Roche, UCB, GSK, Novartis, Maria Tektonidou Grant/research support from: AbbVie, GSK, Genesis, MSD, Novartis, Pfizer, UCB. DOI: 10.1136/annrheumdis-2021-eular.2129

\section{POS1074 $\quad$ CARDIOVASCULAR RISK FACTORS IN A MEXICAN MESTIZO PATIENTS WITH PSORIATIC ARTHRITIS}

S. Lugo-Perez ${ }^{1}$, I. J. Colunga-Pedraza ${ }^{2}$, J. R. Azpiri-López¹, D. Á. GalarzaDelgado $^{2}$, A. B. Rodriguez-Romero ${ }^{2}$, N. Guajardo-Jauregui ${ }^{2}$, D. E. Flores Alvarado ${ }^{2}$, A. Cárdenas ${ }^{2}$, O. Ilizaliturri Guerra ${ }^{2} .{ }^{1}$ Hospital Universitario "Dr. José Eleuterio González", Universidad Autónoma de Nuevo León, Cardiology, Monterrey, Mexico; ${ }^{2}$ Hospital Universitario "Dr. José Eleuterio González", Universidad Autónoma de Nuevo León, Rheumatology, Monterrey, Mexico

Background: Psoriatic Arthritis (PsA) is a chronic inflammatory arthropathy that affects $14 \%-30 \%$ of patients with skin and/or nail psoriasis. Patients with psoriatic arthritis (PsA) have a higher prevalence of traditional cardiovascular (CV) risk factors and an increased risk of developing cardiovascular diseases (1), such as acute myocardial infarction, cerebrovascular accident, peripheral vascular disease and heart failure. Despite the evidence patients with PsA are inadequately screened and undertreated for CV risk factors (CVRF), highlighting a gap in preventive medicine to adjust cardiovascular therapies(2).

Objectives: The aim of the study is to determine the main CVRF in Mexican Mestizo patients with a diagnosis of PsA and to compare it with healthy controls. Additionally, to assess the impact of the diagnosis of PsA on the presence on these cardiovascular comorbidities.

Methods: A cross-sectional, observational, and comparative study of ninety-six patients with PsA between 40-75 years who fulfilled CASPAR criteria 2006. Patients were matched by age and gender with non-PsA subjects. A medical history and physical exam were performed, also a blood sample was collected during the first visit. Chi square and Student's t test were used for comparations between groups. A binary logistic regression was performed including the traditional CVRF (type 2 diabetes mellitus, hypertension, obesity, and active smoking), age and the diagnosis of PsA. A $p$ value $<0.05$ was considered statistically significant.

Results: There were $58(60.4 \%)$ women in each group with a mean of 53 years. Patients with PsA showed a higher prevalence of hypertension (HTN) compared to healthy controls $(35.4 \%$ vs $19.8 \%$, respectively, $p=0.015)$. Additionally, there was a significant difference in the diagnosis of dyslipidemia (42.7\% vs $22.9 \%, p$ $=0.003$ ). We found no statistically difference between the two groups in type 2 diabetes mellitus, active smoking and, obesity (Table 1. below).

Table 1. Comparison of cardiovascular risk factors between Psoriatic Arthritis and controls.

\begin{tabular}{llll}
\hline & PsA & Control & $p$ \\
& $(\mathbf{n = 9 6 )}$ & $\mathbf{( n = 9 6 )}$ & \\
\hline Age, years \pm SD & $53.19 \pm 11.13$ & $53.34 \pm 8.4$ & NS \\
Women, $\mathrm{n}(\%)$ & $58(60.4)$ & $58(60.4)$ & NS \\
T2DM, $\mathbf{n}(\%)$ & $21(21.9)$ & $12(12.5)$ & NS \\
HTN, $(\%)$ & $34(35.4)$ & $19(19.8)$ & $\mathbf{0 . 0 1 5}$ \\
Active smoking, n (\%) & $21(21.9)$ & $20(20.8)$ & NS \\
Dyslipidemia, n (\%) & $41(42.7)$ & $22(22.9)$ & $\mathbf{0 . 0 0 3}$ \\
Obesity, n (\%) & $36(37.5)$ & $25(26.0)$ & NS \\
\hline
\end{tabular}

NS, no significative; SD, standard deviation; HTN, hypertension; T2DM, type2 diabetes mellitus.
The binary logistic regression showed that the diagnosis of PsA (OR 2.235, 95\% Cl 1.141-4.375, $p=0.019$ ) and active smoking (OR 2.429 95\%, Cl 1.137-5.186, $p$ $=0.022$ ) are independent risk factors for the presence of dyslipidemia.

Conclusion: Patients with PsA have a higher prevalence of HTN and dyslipidemia. The diagnosis of PsA seems to be an independent factor for the presence of dyslipidemia. It is important for rheumatologists to identify those patients who could benefit from adjust antirheumatic and cardiovascular therapies due to their impact on morbidity and mortality.

REFERENCES:

[1] Peluso R, Caso F, Tasso M, et al. Cardiovascular Risk Markers and Major Adverse Cardiovascular Events in Psoriatic Arthritis Patients. Rev Recent Clin Trials 2018;13(3):199-209. doi: 10.2174/1574887113666180314105511

[2] Takeshita J, Grewal S, Langan SM, et al. Psoriasis and comorbid diseases: Implications for management. J Am Acad Dermatol 2017;76(3):393-403. doi: 10.1016/j.jaad.2016.07.065

Figure 1. Binary logistic regression for the presence of dyslipidemia.

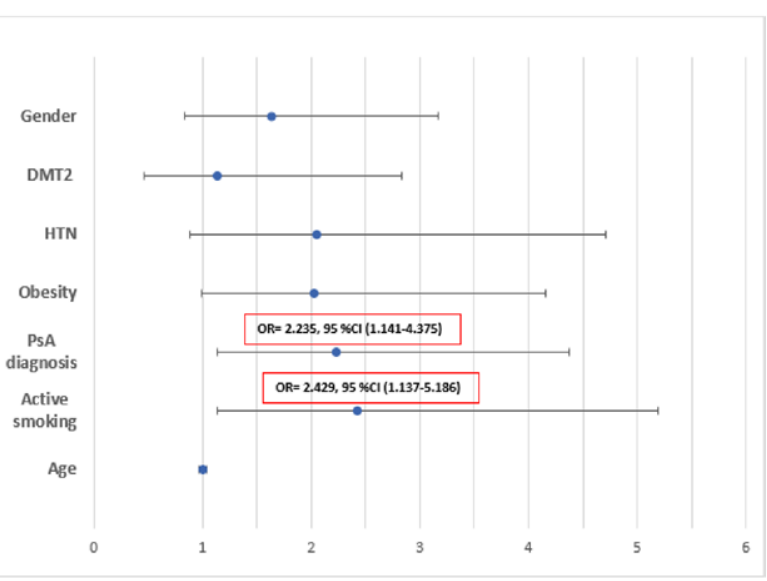

Disclosure of Interests: None declared.

DOI: 10.1136/annrheumdis-2021-eular.2779

\section{\begin{tabular}{|l|l}
\hline POS1075 PREDICTIVE FACTORS ASSOCIATED WITH \\
\hline
\end{tabular} DEVELOPMENT OF PSORIATIC ARTHRITIS IN PATIENTS WITH UNDERLYING PSORIASIS}

W. Y. Loo ${ }^{1}$, F. Yahya ${ }^{1}$, W. H. Han ${ }^{2}$, N. A. A. Fahem², S. S. Yong ${ }^{2}$, L. S. L. Pok ${ }^{1}$ Z. Kwan ${ }^{2}$, Y. C. Tee ${ }^{1} .{ }^{1}$ University of Malaya, Rheumatology Unit, Medicine, KUALA LUMPUR, Malaysia; ${ }^{2}$ University of Malaya, Dermatology Unit, Medicine, KUALA LUMPUR, Malaysia

Background: Psoriatic arthritis (PsA) is a chronic inflammatory condition in which a delayed diagnosis will have health impacts including physical and psychological aspects. Thus, identification of risk factors and early diagnosis are crucial in clinical practice. In Malaysia, $13.7 \%$ of patients with underlying psoriasis develop PsA ${ }^{1}$. However, there are limited data on the risk factors in developing PsA in these patients, not just in Malaysia but also in the Southeast Asia region. Objectives: To analyse sex, clinical features, comorbidities in patients with psoriasis and PsA, and the predictive factors of developing PsA in patients with underlying psoriasis.

Methods: A retrospective study was carried out involving patients with a physician-verified diagnosis of psoriasis who were attending the dermatology and or rheumatology clinics at the University of Malaya Medical Centre, Kuala Lumpur between 2015 to 2020. Data were retrieved from electronic medical records. Data collected included sex, age, body mass index (BMI), duration of psoriasis, socio-demographics, comorbidities, body area affected, severity of skin involvement, presence of nail involvement and systemic therapy used in treating psoriasis. Systemic therapy is defined as methotrexate, sulfasalazine and/or acitretin used before diagnosis of PsA. Patients with psoriasis who developed PsA had information collected on tender joint count, swollen joint count and erythrocyte sedimentation rate (ESR) at their initial visit to the rheumatologist. Logistic regression analyses were performed to identify the possible risk factors of developing PsA. Results: A total of 330 psoriasis patients which included $54.5 \%$ male and a mean age of 53 (standard deviation, SD 18.85) years were included. Eighty-three (25.0\%) patients were diagnosed with PsA. Among patients with PsA, 39.8\% were males with a mean age of 54 (SD 15.79) years. Majority of the PsA patients were ethnic Malay (45.8\%), followed by $28.9 \%$ Chinese and $25.3 \%$ Indian. The median duration of developing PsA was at 36 (IQR 3.5 - 114) months after the 